\title{
Construção de Categorias/Lugares para a Loucura em Relatos de Usuários de CAPS
}

\author{
Alessandra Aniceto Ferreira de Figueirêdo ${ }^{1}$ \\ ${ }^{1}$ Universidade Federal do Rio de Janeiro, RJ, Brasil. \\ Rosineide de Lourdes Meira Cordeiro ${ }^{2}$ \\ ${ }^{2}$ Universidade Federal de Pernambuco, PE, Brasil.
}

\author{
Pedro de Oliveira Filho ${ }^{3}$ \\ ${ }^{3}$ Universidade Federal de Campina Grande, PB, Brasil. \\ Thelma Maria Grisi Velôso ${ }^{4}$ \\ ${ }^{4}$ Universidade Estadual da Paraíba, PB, Brasil.
}

Resumo: Este artigo objetiva investigar as categorias mobilizadas discursivamente por usuários de um Centro de Atenção Psicossocial (CAPS I) para nomearem a si próprios e construírem lugares sociais para si e para as demais pessoas em sofrimento psíquico. Fundamentado na psicologia social discursiva, realizou-se uma pesquisa qualitativa em que se fez uso da observação participante e das rodas de conversa como recursos metodológicos. Os relatos foram submetidos à análise de discurso. Para evitar o uso de categorias excludentes como "louco" ou "loucura" e se posicionando na categoria "normais", os usuários utilizaram categorias como "deficientes", "trauma" e "doença psicológica”. Os participantes da pesquisa definiram a si mesmos como pessoas que levam para a vida toda uma "mancha", o estigma da "loucura", vivenciado nos espaços onde circulam. Apesar disso, em seus relatos, tentaram se apresentar como pessoas iguais às outras, que adoecem e vivem, e que podem circular por vários lugares, não apenas nos hospitais, nos CAPS ou em outros serviços de saúde. Concluiu-se que, com evidente habilidade retórica, os usuários utilizaram categorias discursivas para compreender sua situação e, ao mesmo tempo, combater o processo de estigmatização a que estão submetidos.

Palavras-chave: Discurso, Lugares para Loucura, Usuários de CAPS.

\section{Construction of Categories/Places for Madness in the Reports of Users of Psychosocial Care Centers}

\begin{abstract}
This article aims to investigate the categories mobilized in the discourse of users of a Psychosocial Care Center (CAPS I) to refer to themselves and the social places constructed for them and for other persons in psychological distress. This qualitative research was conducted through participant observation and conversation circles in the light of discursive social psychology. The reports underwent discourse analysis. To avoid the use of excluding categories such as "crazy" and "craziness" while placing themselves within the "normal" category, participants used categories such as "disabled," "trauma," and "psychological illness." The participants also defined themselves as people who carry a "stain" for life, which evinces the presence of a stigma related to "madness" experienced in the spaces where they circulate. Despite this, CAPS users tried to depict themselves as people like others - who get sick, live, and can circulate in various places besides hospitals, CAPS, or other health services. The results indicate that participants employed discursive categories with evident rhetorical ability to understand their situation while combating the stigmatization process that acts upon them.
\end{abstract}

Keywords: Modern terms. Care facilities. Users of mental health services. 


\title{
Construcción de Categorías/Lugares para la Locura en Relatos de Usuarios del CAPS
}

\begin{abstract}
Resumen: Este artículo tiene como objetivo investigar las categorías movilizadas discursivamente por los usuarios de un Centro de Atención Psicosocial (CAPS I), para nombrarse a sí mismos y los lugares sociales que construyen para ellos y para otras personas con problemas psicológicos. Con base en la psicología social discursiva, se llevó a cabo una investigación cualitativa, en la cual los círculos de observación y conversación de los participantes se utilizaron como recursos metodológicos. Los informes fueron sometidos a análisis del discurso. Los usuarios utilizaron categorías como "discapacitado", "trauma” y "enfermedad psicológica” para evitar el uso de categorías excluyentes como “loco” o "locura”, poniéndose en la categoría "normal”. Además, se definieron a sí mismos como personas que llevan una "mancha” de por vida, lo que marca la presencia del estigma de la "locura" que experimentan en los espacios donde circulan. A pesar de esto, en sus informes, intentaron presentarse como las demás personas, que se enferman y viven y pueden circular en varios lugares, no solo en hospitales, CAPS u otros servicios de salud, sino más allá de ellos. Se concluye que, con evidente capacidad retórica, los usuarios utilizaron categorías discursivas para comprender su situación y, al mismo tiempo, para combatir el proceso de estigmatización al que se someten.
\end{abstract}

Palabras clave: Discurso, Lugares para la Locura, Usuarios del CAPS.

\section{Introdução}

Neste estudo, investigamos como as categorias mobilizadas por usuários de um Centro de Atenção Psicossocial (CAPS I) para nomear a si próprios constroem, por meio de seus discursos, lugares sociais para eles e para as pessoas em sofrimento psíquico de uma maneira geral.

Durante séculos, as pessoas em sofrimento psíquico foram classificadas de diversas formas e ocuparam diferentes lugares sociais. Na Antiguidade, eram concebidas como as que recebiam divindades e decifravam mensagens desconhecidas. Na Idade Média, passaram de assessores divinos para pessoas possuídas por entidades malignas (Barroso, Abreu, Bezerra, Ibiapina, \& Brito, 2004). Se até a Renascença a loucura não era mais que um limite material exterior à razão medieval, no século XIV, Foucault (1975) destaca o fato de que ela passa a circular como saber proibido no cerne da própria cultura. Sua circulação, porém, é restrita ao exterior dos muros das cidades. Relegada ao espaço sem partilha dos campos e das águas nas quais flutua a nau dos loucos, a figura obscura e confusa do desatinado é alvo de uma separação ritual (Prado, 2016). Foucault (2010, p. 9) afirma que, nos séculos XV e XVI, "os loucos tinham uma existência errante", uma vez que eram expulsos das cidades, corriam pelos campos ou eram entregues a mercadores e peregrinos. Arte e loucura se imbricavam em personagens fantásticos, o que não se veria no século seguinte, pois a razão passaria a ser tomada como característica do ser humano e a desrazão seria menosprezada, desvalorizada e reduzida ao silêncio.

No século XVII, começaram a ser encarcerados todos os que não podiam contribuir para o movimento econômico-social da burguesia, e, em toda a Europa, foram construídos estabelecimentos de internação, denominados de hospitais gerais, para onde eram enviados todos os que representavam ameaça à ordem social - marginalizados, pervertidos, miseráveis e loucos. Os leprosários e as casas de internamento também foram reconfigurados, passando a ser utilizados para confinar essas pessoas. Para disciplinar os corpos improdutivos e preguiçosos, recorria-se ao trabalho. O confinamento se constituiu, então, como uma medida policial, destinada a oferecer trabalho aos que não poderiam viver sem ele (Foucault, 2010). Nesse período, o hospital funcionava como um misto de exclusão, fruto da preocupação burguesa de colocar ordem no mundo da miséria, de assistência, com o dever da caridade e da hospitalidade da Igreja, 
e de apoio espiritual. Era uma prática desenvolvida ainda nos leprosários, mas deslocada para doentes, loucos, devassos, prostitutas etc. O espaço hospitalar ainda não era uma instituição médica por excelência, segundo Foucault (1992).

O discurso médico se fundava nos grandes tratados clássicos da medicina em que se criou o conceito de alienação mental (mentis alienatio), especificamente na obra de Félix Plater, em 1625. Nesse período, foi apresentada a primeira classificação da alienação, inspirada nos erros ou nos defeitos de funcionamento da razão, da imaginação e da memória (Pessotti, 1999). No século XIX, Pinel e a psiquiatria encontraram os loucos encerrados em muros. Com o objetivo de libertá-los, romperam as correntes que os prendiam. Todavia, foram instalados em um espaço hospitalar específico e mantidos no campo da exclusão, por meio do isolamento e da vigilância médica (Foucault, 2010).

O saber psiquiátrico tomou para si a nomeação e o cuidado da loucura. Se, antes, o sujeito era tomado ora como entidade divina ou mística, ora como vítima de possessão demoníaca, passou a ser denominado de alienado. Nesse contexto, a alienação mental vai indicar "um distúrbio no âmbito das paixões, capaz de produzir desarmonia na mente e na possibilidade objetiva de o indivíduo perceber a realidade" (Amarante, 2007, p. 30).

De acordo com Foucault (2010), o saber psiquiátrico propunha um tratamento humanitário para os alienados, que se baseava em cuidadosa observação, elaboração de registros diários e aplicação de práticas de coerção moral. Dentro do hospital psiquiátrico, os médicos separavam os alienados por espécies, os afastando de seus familiares e das pessoas ditas sãs, com o argumento de que o meio poderia contaminá-los durante seu tratamento. Assim, o hospício foi tomado por Pinel e por outros profissionais da época como uma instituição, por si só, terapêutica. Esquirol, discípulo de Pinel, passou a destacar um substrato orgânico específico para cada forma de loucura. A partir dessa leitura, o alienado tornou-se doente mental. No final do século XIX, a doença da mente foi materializada, na nosologia, a partir dos órgãos do cérebro, e a loucura passou a ser caracterizada como doença do cérebro, remetendo à dicotomia cartesiana entre mente e corpo. Ao localizar a causa do adoecimento no corpo do doente, a psiquiatria ratificou seu espaço nas ciências médicas e foi além da metafísica para definir um fenômeno que perseguiu durante séculos (Pessotti, 1999). Como adverte Prado (2016, p. 224), nesse processo "de relegado ao exterior dos muros das cidades, o desatinado é aprisionado no interior de um espaço inabitável, inacessível e sem partilha possível. Este movimento continuado tem seu ponto culminante no enclausuramento do louco em sua própria subjetividade".

O século XX trouxe o organicismo de Kraepelin para fundamentar a classificação das doenças psiquiátricas, apresentando uma perspectiva que buscava a correlação entre sintomas psíquicos e alterações cerebrais para descrever e tratar a doença mental. Bleuler, como edificador do termo esquizofrenia, e Freud, com a elaboração do conceito de motivação inconsciente, fizeram emergir os processos psíquicos como fundamentais para explicar a loucura, e as doenças deixaram de ser apenas cerebrais e passaram a ser psicológicas (Pessotti, 1999).

Foi somente depois da Segunda Guerra Mundial (1939-1945) que a sociedade passou a questionar os ideais modernos de valorização da máquina e do ser humano dotado de razão. Isso porque esses ideais haviam desencadeado práticas excludentes e violentas contra os seres humanos definidos como inferiores, atípicos e irracionais, similares ao sofrimento imposto aos judeus, negros e homossexuais nos campos de concentração nazista e em espaços de reclusão, como os hospícios e as colônias terapêuticas, ocupados pelos chamados doentes mentais (Amarante, 2007). Nesse contexto, surgiram vários movimentos denominados antipsiquiátricos. Em países como a Inglaterra, os Estados Unidos, a França e a Itália, foram tomadas algumas iniciativas para transformar as práticas institucionais que ficaram conhecidas por Reforma Psiquiátrica (Desviat, 2008).

No Brasil, o movimento antimanicomial culminou com a Reforma Psiquiátrica Brasileira, que atingiu a esfera do Poder Legislativo na década de 1990 e foi "materializada" na aprovação da Lei no 10.216, de 6 de abril de 2001, que dispõe sobre "a proteção e os direitos das pessoas portadoras de transtornos mentais e redireciona o modelo assistencial em saúde mental no país” (Brasil, 2001). Segundo Amarante (2007, p. 70), essa lei não assegurou todas as aspirações do projeto anterior, como a extinção progressiva dos manicômios, mas "revogou a arcaica legislação de 1934, que ainda estava em vigor, e significou um avanço considerável no modelo assistencial", pois, dentre outros 
aspectos, objetivou resgatar a liberdade e ressaltar o direito à cidadania das pessoas que necessitavam de assistência em saúde mental.

A reforma foi responsável pela criação de novas maneiras de atender as pessoas em sofrimento psíquico, visto que propôs a criação de outros equipamentos de atenção à saúde mental, como os Centros de Atenção Psicossocial (CAPS) ${ }^{1}$, que visam substituir o hospital psiquiátrico por outras propostas de tratamento, reconfigurando o cuidado em saúde mental para um espaço aberto: a esfera comunitária e social (Ministério da Saúde, 2005).

Os CAPS, as residências terapêuticas, as unidades de saúde da família, os restaurantes, as praças e as casas transbordaram os limites físicos das paredes e das grades dos hospitais psiquiátricos. Dessa forma, esses sujeitos passaram a frequentar outros lugares ou espaços e a ter outras classificações, como pessoas em sofrimento mental ou sofrimento psíquico, usuários². Como bem destaca Vieceli (2014, p. 7): "Abandona-se o confinamento entre muros, a clausura dos gabinetes, e se ocupa o bairro, a rua, a praça. Esse movimento implica em um novo e grande desafio: o encontro da cidade com o louco e a loucura". Gradualmente, construiu-se "um novo lugar social para a loucura” (Amarante \& Torre, 2017). Os referidos autores, no entanto, reconhecem que várias experiências reformistas fizeram "reacomodações" e não conseguiram se desvencilhar totalmente dos "fundamentos tradicionais da Psiquiatria". Nesse sentido, vale destacar que o modelo manicomial não foi totalmente superado. Sander (2010) assevera que se mantiveram inúmeras e sofisticadas formas de enclausuramento em que se confinou a desrazão, dentre as quais, a que Pelbart (1989, citado por Sander, 2010) denomina de "manicômios mentais".

Inúmeros são os desafios enfrentados, sobretudo, neste momento da vida nacional, em que, devido à ascensão da ultradireita ao poder, os avanços da
Reforma Psiquiátrica Brasileira estão ameaçados. Há um processo acelerado de desmonte desse movimento, em que a rede de serviços de base comunitária, assim como o orçamento para esses serviços, têm sido paulatinamente reduzidos (Delgado, 2019). Amarante e Nunes (2018, p. 2073) denunciam que, a partir de 2015, o Ministério da Saúde e, por conseguinte, os princípios do Sistema Único de Saúde (SUS) foram alvos de negociação política, o que resultou em mudanças. Em seguida, com a "instalação do estado de exceção", as mudanças e os retrocessos foram se tornando radicais, como é o caso da Resolução no 32 , de 14 de dezembro de 2017, aprovada pela Comissão Intergestores Tripartite, que como alertam os referidos autores, retomou o modelo manicomial, dando início a um "processo de desmontagem” da proposta reformista.

No período de dezembro de 2016 a maio de 2019, foram editadas, aproximadamente, quinze normativas, entre portarias, resoluções, decretos e editais, que formam o que a nota técnica no 11/2019 CGMAD/DAPES/SAS/MS denominou de "Nova Política Nacional de Saúde Mental” - PNSM (Brasil, 2019; Cruz, Gonçalves, \& Delgado, 2021). Uma das propostas dessa "nova política", segundo Martins (2019), é a centralidade dos hospitais psiquiátricos e das comunidades terapêuticas no novo caminho que está sendo construído para a Política Nacional de Saúde Mental, Álcool e outras Drogas (PNSMAD).

Mediante tais acontecimentos, diversas entidades, como Conselho Nacional de Saúde ([CNS], 2018), Conselho Nacional de Direitos Humanos ([CNDH], 2019), Associação Brasileira de Saúde Mental ([Abrasme], 2019), Associação Brasileira de Saúde Coletiva ([Abrasco], 2017), Conselhos Federais de Psicologia ([CFP], 2017) e de Enfermagem ([Cofen], 2017), têm apontado o grande retrocesso à Reforma Psiquiátrica Brasileira em função da edificação dessa "nova política". Esses questionamentos reiteram que o que foi construído pelo movimento antimanicomial

\footnotetext{
${ }^{1}$ De acordo com a Portaria no 336/2002, há os seguintes tipos de CAPS: CAPS I, CAPS II, CAPS III, CAPSI e CAPSad (Ministério da Saúde, 2002). O CAPS I é um serviço para cidades de pequeno porte, que devem dar cobertura, durante o dia, para adultos, crianças e adolescentes com transtornos mentais severos e pessoas com problemas devido ao uso de álcool e de outras drogas. Já os CAPS II são serviços para cidades de médio porte e atendem, durante o dia, à clientela adulta. Os CAPS III são serviços $24 \mathrm{~h}$, geralmente disponíveis em grandes cidades, que atendem à clientela adulta. Existem também os CAPS i, que são serviços para crianças e adolescentes em cidades de médio porte e que funcionam durante o dia, e os CAPS ad, voltados a pessoas com problemas relacionados ao uso de álcool ou outras drogas. Geralmente disponível em cidades de médio porte, esse serviço funciona apenas durante o dia. O CAPSad III funciona durante 24 horas (Brasil, 2004).

${ }^{2}$ Utiliza-se, neste artigo, a categoria pessoa ou sujeito em sofrimento psíquico ou mental, adotada por Amarante (2007), que se centra na compreensão de um sujeito que sofre, para evitar a patologização presente em algumas caracterizações psiquiátricas e psicológicas. Também utilizamos a categoria usuário, pois entendemos que remete a "desfrutar de algo coletivo", como visto no dicionário Aurélio (2010), mesmo que esse desfrutar nos encaminhe, inicialmente, ao sistema de saúde.
} 
ainda não foi destruído, nem o será facilmente, porque esse é um movimento profundamente conectado aos ideais emancipatórios que constituíram as práticas de saúde mental no mundo ocidental na segunda metade do século XX e é apoiado consideravelmente por profissionais de saúde mental no Brasil.

Nesse contexto, estudos como o de Bongiovanni e Silva (2019) se propõem a refletir sobre esses desafios e sobre o processo de desinstitucionalização nos serviços substitutivos, como os CAPS. Para tanto, as referidas autoras realizaram uma pesquisa-intervenção por meio de oficinas com usuários de um CAPS de Porto Alegre, com o intuito de descrever o percurso pela cidade de usuários com longa trajetória e permanência nesses centros. Outros estudos, como os de Grigolo (2010) e Henriques (2012), também realizaram pesquisas com usuários de CAPS e argumentaram que ouvir as falas desses sujeitos é indispensável para que possamos compreender o encontro da loucura com a cidade a partir do lugar daqueles que sofrem. Esses estudos foram feitos em serviços que se propõem a desconstruir a lógica manicomial de cuidado, fazendo uma prática articulada no território onde a pessoa reside ou próximo de sua comunidade, tomando como base a constituição de uma rede de atenção psicossocial que, segundo Amarante (2007, p. 86), forma "uma série de pontos de encontro, de trajetórias de cooperação, de simultaneidade de iniciativas e atores sociais envolvidos", sendo por meio dela que os sujeitos são usuários dos serviços de saúde.

Atento a esses processos, este estudo acolheu as palavras das pessoas em sofrimento psíquico para mostrar o modo como constroem a si mesmas e sua experiência com a loucura. Como ressalta Chaves (2009, p. 59, grifo do autor), "esse caminho se refere à tentativa de alcançar o 'ponto de vista' desses sujeitos, ouvindo suas palavras recolhidas". Partimos do pressuposto segundo o qual as categorias discursivas existentes para a loucura produzem discursivamente lugares sociais que favorecem, ou não, a circulação dessas pessoas nas esferas sociais e comunitárias.

\section{Método}

Realizou-se uma pesquisa de abordagem qualitativa cujo aporte teórico-metodológico foi a psicologia social discursiva. Conforme Potter e Hepburn (2007) discutem, em vez de tentar investigar as ideias que as pessoas trazem "dentro de suas cabeças", os psicólogos discursivos focam seus estudos na natureza retórica do discurso, porque entendem que os fenômenos psicológicos são construídos na interação entre os sujeitos, e se voltam para analisar as falas e os textos emitidos pelas pessoas em ações cotidianas. Como asseveram Wetherell e Potter (1992), nessa perspectiva se enfatiza o uso dos discursos em determinadas situações, ou seja, se considera o discurso no momento em que ele é produzido. Dito de outro modo, o discurso é analisado nas conversações, no bate-papo do dia a dia, nos textos do cotidiano, em que são observados as funções discursivas, as estratégias retóricas e os efeitos dessas produções discursivas. Nessa perspectiva, o discurso é entendido como uma prática social em que a atenção se volta para o modo como ele se atualiza nas interações cotidianas, moldando, simultaneamente, essas interações. Examina-se, também, como alguns discursos trabalham juntos e contra outros discursos. Portanto, nessa perspectiva teórica, as formulações discursivas são formas de ação social que apresentam versões de mundo e de nós mesmos, produzindo sujeitos, grupos e relações sociais.

A investigação foi desenvolvida no CAPS I da cidade de Itaporanga, Paraíba ${ }^{3}$, no período de fevereiro a julho de 2012, quando a pesquisadora e autora deste trabalho morou na cidade, onde já havia trabalhado anteriormente - o que facilitou os contatos com usuários e profissionais e a própria realização da pesquisa. A escolha por trabalhar com usuários de CAPS se justifica por causa da necessidade de escutar os sujeitos aos quais foi destinado, historicamente, o silêncio; ou seja, aqueles de quem a sociedade, comumente, espera pouco ou quase nada.

A pesquisa foi desenvolvida em duas etapas consecutivas. Na primeira, realizou-se a observação participante, da qual todas as pessoas que circulavam no CAPS I fizeram parte. Na segunda, foi feita a montagem das rodas de conversa com os usuários do CAPS. Neste trabalho, a análise terá por foco os diálogos realizados nessas rodas, de que fizeram parte sete usuários: dois homens com idades entre 46 e 57 anos e cinco mulheres entre 25 e 58 anos, que frequentavam a instituição há um ano ou mais e aceitaram o convite para participar das rodas.

\footnotetext{
${ }^{3}$ A população de Itaporanga apresenta 23.192 habitantes, distribuídos numa área territorial de 468 km² (Instituto Brasileiro de Geografia e Estatística [IBGE], 2010). Destaca-se das outras cidades do Vale do Piancó (alto sertão da Paraíba) pela efetivação de um polo industrial (têxtil).
} 
Realizaram-se quatro rodas de conversa, uma por semana, com duração média de uma hora e vinte minutos. No primeiro encontro, foram utilizados os seguintes recursos: espelho grande, peças de roupas e acessórios (relógio, pulseira, batom, chapéu, lenço, tênis, sandália, celular, brincos etc.). A dinâmica consistia em um usuário "montar" o outro a partir das peças expostas na sala. Em seguida, haveria uma discussão sobre como eles se percebiam, o que sentiam ao estar daquela forma e como desejavam estar e ser percebidos. No segundo, refletiu-se sobre os lugares em que os usuários circulavam e onde não circulavam e quais os espaços que ocupavam. Para tanto, utilizou-se como recurso uma maquete, que simbolizava uma cidade, com ruas, casas, CAPS, delegacia, hospital, escola etc. Um boneco foi usado para representar uma pessoa em sofrimento psíquico, e os participantes do grupo o guiaram pela cidade, mostrando os espaços por onde ele iria ou não circular. O terceiro teve como objetivo trabalhar as categorizações das pessoas em sofrimento psíquico. Duas cartolinas foram fixadas na parede; em uma delas, os usuários colocaram os termos pelos quais eles eram chamados no dia a dia, e, na outra, as palavras ou frases com que desejavam ser nomeados. A discussão foi desenvolvida a partir das escolhas feitas. No quarto encontro, avaliaram-se as rodas de conversa.

As rodas foram gravadas em áudio e transcritas na íntegra, e as observações foram registradas em um diário de campo. Seguimos as indicações de Gill (2008), a transcrição não pode se constituir como uma síntese da fala, nem deve se orientar pela limpeza e pela correção do que foi dito, mas ser feita pelo registro literal. Além disso, levamos em consideração a entonação do que era dito, os silêncios, as pausas e os gestos expressos pelos membros das rodas, conforme orientam Potter e Wetherell (1987).

Depois de uma leitura exaustiva do material transcrito e do diário de campo, foi possível organizar os discursos dos participantes da pesquisa em categorias, tomando como base o objetivo do trabalho e de acordo com a proposta de análise de discurso da psicologia social discursiva (Gill, 2008; Potter \& Wetherell, 1987).

Para o desenvolvimento deste trabalho, foram consideradas as questões éticas contidas na Resolução no 466/2012 do CNS, que determina as exigências éticas e científicas propostas para desenvolver pesquisas e o consentimento livre e esclarecido dos sujeitos que participaram do estudo. Para manter o anonimato dos participantes, seus nomes foram substituídos por pseudônimos. Essa pesquisa foi submetida e aprovada pelo Comitê de Ética da Universidade Estadual da Paraíba (UEPB).

\section{Resultados e discussão}

Os participantes da pesquisa buscaram, incessantemente, evitar o uso de categorias como "louco" ou "loucura" para definir a si mesmos, recorrendo a termos como "deficiência", "trauma” e "doença" para falar de seu sofrimento. Descreveram os aperreios, as crises e suas experiências nas clínicas psicológicas e nos manicômios, questionando o discurso segundo o qual seriam "doidos".

\section{Os usos da doença para falar sobre o sofrimento}

Algumas vezes, os usuários do CAPS se definiram (ou àqueles que frequentam a instituição) como deficientes; posicionaram-se como pessoas que têm uma deficiência mental e se colocaram fora de categorias como "loucos" ou "doidos", que são, em nossa sociedade, a personificação da desrazão, como se pode constatar neste relato de Lara:

Lara: ... quem vive aqui no CAPS, eles não são loucos, são deficientes.... Pode você sentir uma dor de cabeça todo dia, vocêé deficiente sim, daquela dor de cabeça! [ênfase]

Pesquisadora: Hum...

Lara: Daí foi que eu fui entender o sentido quando você é deficiente, é só se for aleijado, doido ou essas coisas, mas, não. Não é.

Branca: Qualquer problema é deficiente.

Lara: Têm vários tipos de coisa que é deficiente. Eu sou uma! [ênfase]

No diálogo acima, dois processos discursivos interdependentes estão presentes: a categorização e a particularização. De acordo com Billig (1987), a categorização é o processo por meio do qual inserimos elementos numa categoria para torná-los semelhantes a todos os outros elementos da categoria. A particularização é o processo inverso, por meio do qual um elemento é retirado de uma categoria em que havia sido colocado anteriormente, ou é diferenciado desde o início dos outros elementos dela. Lara, ao dizer que os que vivem no CAPS “não são loucos, são deficientes", 
emprega, primeiramente, a estratégia retórica da particularização (os usuários "não são loucos"), e, depois, a estratégia da categorização, que consiste em igualar os elementos da categoria usuários do CAPS aos elementos que fazem parte da categoria "deficientes". Nessa passagem, os usuários são retirados da categoria "loucos" e colocados na categoria "deficientes". Em seguida, afirma: "Daí foi que eu fui entender o sentido quando você é deficiente, é só se for aleijado, doido ou essas coisas, mas, não. Não é". Nessa intervenção discursiva, cuja forma dificulta o entendimento do conteúdo, ela parece estar afirmando que há uma interpretação equivocada, segundo a qual só é deficiente quem é "aleijado", "doido" ou outros tipos de pessoas que se assemelham a eles ("essas coisas"); que outros tipos de pessoas que não se assemelham aos "aleijados" e "doidos" etc. também são deficientes.

As duas intervenções seguintes, de Branca e da própria Lara ("qualquer problema é deficiente", "têm vários tipos de coisa que é deficiente. Eu sou uma!”), reforçam essa interpretação. Portanto, os usuários do CAPS fazem parte de uma ampla categoria junto com os "loucos", a categoria dos "deficientes", mas a diferença entre essas duas subcategorias, usuários e "loucos", é enfaticamente ressaltada.

Há que se destacar o uso da categoria "problema" na fala de Branca. Silva (2012), em pesquisa com familiares de usuários de um CAPS, analisou a presença frequente da categoria "problema" para caracterizar o sofrimento psíquico, utilizada de modo generalista e que abarca qualquer tipo de manifestação do sofrimento. Segundo a autora, ao usar essa categoria, os familiares aproximavam os usuários do restante da humanidade, afinal, toda pessoa tem algum tipo de problema. Com essas estratégias descritas, tanto Lara quanto Branca procuram se dissociar de uma classificação que as desqualificaria socialmente, ao mesmo tempo em que tentam se aproximar de características das pessoas ditas normais.

Os usuários também usaram o termo "doença psicológica" para categorizar a si próprios. Mais uma vez, distanciaram-se de categorias como "loucos" ou "doidos" e de seus efeitos, que interpretam, tacitamente, como excludentes.
Pesquisadora: Por que vocês acham que Deivisson $^{4}$ foi encaminhado para ir para o CAPS?

Branca: Porque a doença dele era ... [pausa] psicológica, né?

Lara: Bom, já que você trouxe esse boneco de lá pra cá, e trouxe do hospital aí, essa história aí, tá batendo com a minha história.

Pesquisadora: É, Lara?

Márcia: Com a dela.

Lara: Tá batendo com a minha história.

Pesquisadora: Por quê?

Lara: Porque a minha história vem de lá até o hospital, do hospital é que me enviaram pro CAPS....

Não é de qualquer doença que Branca, Lara e Márcia falam, mas da doença psicológica, que se diferencia de outras e que as diferencia de outras pessoas. A doença pode ser tratada, e as usuárias sabem que qualquer pessoa pode experienciar um problema, que alguns têm, mas que pode ser tratado numa instituição específica: no CAPS, como destaca Lara. Além disso, quando as usuárias se posicionam, passam a se reconhecer também como grupo que tem a mesma história: "aí, essa história aí, tá batendo com a minha história”.

Essas definições mobilizam e reproduzem saberes socialmente aceitos - o psicológico, o psiquiátrico e o psicanalítico, e tal mobilização no modo como essas pessoas definem a si próprias torna mais fácil a aceitação delas nos locais onde vivem com outras pessoas e no CAPS. Vechi (2004, p. 494) ressalta que, apesar das "reformas discursivas e dos procedimentos assistenciais associadas a ela [a loucura], o efeito de favorecer a permanência em uma condição reconhecida como patológica foi um aspecto presente no processo de introdução e manutenção da loucura como objeto da ciência". Então, ao inserir a "loucura" na categoria "doença" a ser tratada, esses sujeitos entram na lógica da ordem social e do pensamento científico objetivo, como se refere Basaglia (2005).

Outra categoria do saber psicológico ou psicanalítico mobilizada nessa perspectiva é o "trauma", como se pode perceber na fala de Cesare, a seguir:

\footnotetext{
${ }^{4} \mathrm{Na}$ segunda roda de conversa, foi utilizada como recurso uma maquete, que representava uma cidade com casas, ruas, árvores, igrejas, bares etc., e um boneco, como já mencionado. Deivisson foi o nome dado pelos participantes da roda ao boneco, que representava uma pessoa em sofrimento psíquico e que circulava pela cidade.
} 
Cesare: O doutor lá de João Pessoa me avaliou com um, um... trauma. Ele colocou...

Pesquisadora: Um trauma?

Cesare: Um trauma. E ele conversou com a minha mãe, perguntou se eu bebia, se eu fumava. Aí ela disse: "ele não faz nada disso. Tem hora que ele tá discutindo, depois fica bem". Porque se fumasse e bebesse bebida alcoólica ele [o médico] disse talvez não teria recuperado....

Trata-se de mais um termo mobilizado para posicionar o sujeito que fala a salvo dos efeitos excludentes que atingem todos os que são categorizados como "loucos" ou "doidos". A exclusão, como pontua Prado (2016, p. 229), está presente na história da loucura desde o momento em que o desatino ocupou o lugar da lepra. $\mathrm{O}$ autor ressalta que a loucura "nasceu definitivamente do fenômeno da exclusão".

No relato de Cesare, os efeitos de seu "trauma" (mencionado depois de clara hesitação) se resumem a uma predisposição para discutir que não é permanente ("tem hora que ele tá discutindo, depois fica bem"). O uso do discurso direto, que reproduz a fala da mãe de Cesare tal como ela teria ocorrido, tem a capacidade de dar mais crédito ao que ele afirma, pois a reprodução literal de um enunciado coloca o falante como alguém que esteve presente e que, por isso, testemunhou a cena, como afirma Potter (1998). Mas, antes de mencionar essa predisposição para entrar em discussões, Cesare, para amenizar os eventuais efeitos negativos do que diria logo em seguida, apresenta-se, mais uma vez, por meio da voz de sua mãe, como alguém que não bebe nem fuma. Recorrendo ao saber médico, ele legitima o que está afirmando: "Porque se fumasse e bebesse bebida alcoólica ele [o médico] disse talvez não teria recuperado".

"Pessoa que é fraca" é outra expressão usada pelos usuários quando falam de si próprios.

Caxingo: O pessoal do mundo gosta de ver a pessoa que é fraca aperreada.

Lara: Muito bem!

Márcia: Fica aperreando...

Pesquisadora: Como é, Caxingo?

Caxingo: O pessoal do mundo gosta de ver a pessoa aperreada.

Caxingo afirma que "o pessoal do mundo gosta de ver a pessoa que é fraca aperreada". Logo em seguida,
Lara e Márcia apoiam a intervenção dele. A última afirma que o "pessoal do mundo" fica aperreando. Eles descrevem um tipo de situação muito comum no cotidiano das pequenas cidades, onde a interação face a face é muito intensa e há uma rede de observação sobre a vida dos moradores, a circulação e os eventos (Comerford, 2003). Em maior ou menor medida, todos observam e são observados e, aparentemente, nada escapa ao olhar e aos "mexericos". Nesses contextos, não é incomum que as pessoas em sofrimento psíquico se tornem alvo das atenções, das brincadeiras, das zombarias e das crueldades. Muitas vezes, os vizinhos e conhecidos costumam usar apelidos para irritar essas pessoas.

A expressão "pessoa que é fraca" constrói sutilmente, para os usuários, uma identidade em que não há insanidade, predisposição para a violência ou qualquer outro traço que provoque medo ou pavor, uma identidade cujo traço definidor é uma fraqueza que, entre outras coisas, torna essas pessoas emocionalmente vulneráveis quando são provocadas. Nada na expressão "pessoa que é fraca" nos induz a pensar em um desarranjo afetivo exacerbado e fora de controle, como, em geral, espera-se do louco nas sociedades modernas (Pacheco, 2011). A expressão "pessoa que é fraca" sugere um desarranjo emocional ameno, leve, sem consequências funestas. Trata-se de um modo de organizar retoricamente o discurso, cujo efeito discursivo é a formulação de uma identidade para os usuários dos CAPS sem o traço de periculosidade, que, como mostram diferentes autores (Barbosa, Caponi, \& Verdi, 2018; Barros-Brisset, 2011; Oliveira \& Rodrigues, 2016; Peres, Moser, Oltramari, \& Rodriguez, 2012), é muito persistente nos discursos dos mais diferentes grupos em nossa sociedade quando falam sobre pessoas em sofrimento psíquico.

Intervenções como essa e outras analisadas neste trabalho mostram que esses sujeitos, que são tão desqualificados quando avaliados em termos de capacidades argumentativas e cognitivas, apresentam uma evidente habilidade retórica na realização do processo de gerenciamento da identidade que tem sido tão estudado pelos teóricos da psicologia social discursiva (Potter, 1998; Wetherell \& Potter, 1992).

\section{Contextos de mobilização das categorias "loucos" $\mathrm{e}$ "doidos"}

Como observado anteriormente, os usuários do CAPS procuraram continuamente, nas rodas de con- 
versa, usar termos para definir a si próprios que não os posicionassem como loucos. Não poderia ser diferente. Como afirma Grigolo (2000), pessoas em sofrimento psíquico não se identificam com o estereótipo do louco, embora reproduzam o discurso manicomial. Para elas, segundo a autora, "doido" (ou "louco") é uma pessoa alienada, que passa longo período internada em hospitais psiquiátricos e é caracterizada pela agressividade, pela violência, pela capacidade de matar. Em função disso, o uso dos termos "doido", "louco", "doidinha" é compreendido como uma violência, uma agressão.

Nesta pesquisa, em situações diferentes das rodas de conversa, as categorias "loucos" e "doidos" foram usadas para agredir outros usuários do CAPS e para realizar outros tipos de ação. Em uma dessas situações, Raia classifica outra usuária (que não participou das rodas de conversa) de "doidinha". Diz que ela, que chegou recentemente à instituição, faz gestos repetitivos durante as oficinas, como se estivesse contando dinheiro, por isso diz que ela seria "doidinha". Lara a contesta, dizendo que "doido" é aquele que é agressivo, e fala de um primo de quem cuida e que é "doido". Branca diz que ninguém do CAPS é "doido", as pessoas ali teriam "problemas". Alice concorda com Branca. Raia reconsidera sua avaliação e diz que "doido" é "aquele que rasga dinheiro". Lara afirmou que já viu muita gente rasgando dinheiro sem ser "doido", e muito "doido" que não rasga dinheiro.

Em outra situação, Alice chama Raia de "doida", diz que vai receber a aposentadoria e ter muito dinheiro e que as pessoas têm inveja dela. Raia fala que não tem inveja de ninguém e que não precisa ser sustentada porque não é preguiçosa, consegue trabalhar. Alice a chama de "doida" e diz que não trabalha porque o pai a sustenta, e ela vai ganhar muito dinheiro. Raia diz que foi agredida, se irrita, começa a bater na mesa e fala (alto) que não vai mais tratar bem as pessoas. Alice diz que também é "doida" e não se incomoda; fala que tudo o que disse foi sem pensar; pede desculpas, mas Raia continua reclamando.

O emprego da categoria "doida" remete à agressividade, a falar sem pensar. Por sua vez, "doidinha" tem um sentido pejorativo, indica alguém com conduta bizarra. De acordo com Duarte (1986), essas categorias caracterizam a falta em relação ao mundo, o afastamento da racionalidade que sustenta os sujeitos e faz com que sejam aceitos socialmente. Afinal, para usar o repertório de Goffman (1988), o transtorno psicológico é um daqueles atributos que diminuem e depreciam uma pessoa em nossa sociedade e deterioram sua identidade; um estigma que essas pessoas carregam em todos os contextos e que produz tensão e sofrimento permanentes. É a figura do estranho que se constitui nesse processo de diferenciação entre nós, os normais, e eles, os anormais. Os anormais constituem a categoria dos estigmatizados, a quem são atribuídas características inferiores, muitas vezes associadas a animais, à sujeira, à preguiça e à fraqueza. Esse estigma figura para os usuários do CAPS como uma fonte de intenso sofrimento, que cria barreiras para realizar projetos pessoais, conforme discutiram Moraes et al. (2018) em sua pesquisa acerca da loucura e do cuidado de enfermagem voltado para pessoas com sofrimento mental.

Como atestam Miranda e Cabral (2016), de maneira geral, atribui-se uma valoração negativa à experiência da "loucura", porque, mesmo que a sociedade compartilhe com esses sujeitos quereres, gostos e escolhas, se vem de alguém denominado, em dado momento, como "louco", essas ações tomam proporções outras que se tornam um "anunciador de crise".

Nas duas situações apresentadas nos relatos de Alice e de Raia, esses termos são empregados com os sentidos supracitados, porém, mais do que expressar crenças ou representações cognitivas das usuárias, realizam ações, como é próprio de todas as construções discursivas (Gill, 2008; Potter, 1998; Potter \& Wetherell, 1987). Usados em um contexto de maledicência e de conflito, servem para acusar, agredir ou, até mesmo, amenizar o impacto de uma agressão verbal, como ocorre quando Alice afirma que também é "doida", depois de dizer que Raia é "doida".

Na primeira situação descrita, deve-se ressaltar, mais uma vez, o uso da categorização e da particularização (Billig, 1987) no debate sobre as usuárias para definir o que é próprio da loucura. Ora os "doidos" são colocados em categorias ("doido é aquele que é agressivo"; “doido é aquele que 'rasga dinheiro'”), ora uma pessoa que fora colocada na categoria "doida" é retirada dela (quando Raia reconsidera sua avaliação de uma usuária que havia sido classificada como "doida"), ora as pessoas que "rasgam dinheiro" são retiradas da categoria "doidas".

\section{Existem lugares para a loucura?}

Durante a segunda roda de conversa, os participantes da pesquisa puderam falar, mais especifi- 
camente, sobre os lugares por onde as pessoas em sofrimento psíquico circulam ou poderiam circular. Nessa roda, os usuários olhavam a maquete que simbolizava uma cidade e tentavam identificar quais os lugares que lá existiam, como a sorveteria, a pizzaria, o cabaré , o bar, a escola, e os que faltavam, como o posto de gasolina, a igreja evangélica, entre outros por eles apontados. Houve uma intensa discussão para definir o nome da cidade. Vários locais que eles conheciam foram mencionados, até que o grupo decidiu denominá-la de Itaporanga, Paraíba. Os usuários também escolheram o nome do boneco que andaria pela maquete - Deivisson -, sugerido por Alice. O diálogo do grupo se desenvolveu entre concordâncias e discordâncias, com o levantamento de questões que eram lançadas para seus membros. Entre uma indagação e outra, o boneco circulava pelos espaços da cidade, como o CAPS, a cadeia, o hospital, a praça, a sorveteria, e a discussão tomava corpo.

Cesare: Assim, na minha imaginação, eu tenho vontade de ir festa assim, fora da cidade assim, pra outras cidades, mas eu nem penso em ir... porque a gente chega pela manhã e ela [a mãe] tá... esperando, preocupada.

Pesquisadora: Tu queria ir a festa fora da cidade. Você acha que ia se sentir bem...?

Alice: Tu foi, Cesare, pra festa?

Cesare: Fui.

Alice: Mainha estava lá também, tu não viu ela não? Raia: Eu gosto assim, de ir pra um restaurante, de música ao vivo, MPB, música clássica.

Pesquisadora: É? Música de MPB, música clássica. Raia: É. No barzinho, eu fui. Mas, festa de forró...

Márcia: No aniversário de [ininteligível] já fui pra pizzaria...

Raia: Na pizzaria é bom, Márcia!

Pesquisadora: Na pizzaria, né, Márcia?

Alice: Não, ir na pizzaria pra lanchar é bom, agora sair pra passar a noite toda...

Raia: A noite toda, Deus me livre!

Pesquisadora: Lanchar é bom, Alice?

Alice: É, todo mundo gosta de sair pra lanchar... Branca: É, sair pra lanchar é bom.
Raia: Eu vou pra Vale do Amanhecer ${ }^{6}$ [templo espírita].

Pesquisadora: Vai pra Vale do Amanhecer?

Branca: Eu vou pra igreja católica.

Raia: Mas eu vou pra igreja católica também!

Pesquisadora: Igreja católica. E como é que vocês se sentem nesses lugares?

Márcia: Eu me sinto bem lá! [ênfase]

Raia: Lá no Vale do Amanhecer é bom.

No que diz respeito à circulação pela cidade, sair para lanchar é algo de que "todo mundo gosta", como diz Alice. Tal atividade (assim como ir à pizzaria ou a um restaurante, ouvir música, dançar...) reitera a posição dos usuários como pessoas que são iguais a quaisquer outras. No entanto, ir para festa de forró e dançar a noite toda não são atividades que os sujeitos da pesquisa realizam.

O problema é "sair para passar a noite toda", como refere Alice, mesmo que não seja para ir à festa. Sair de casa e passar a noite inteira fora implica ficar suscetível a quaisquer eventos que possam acontecer, como não se sentir bem no dia seguinte ou passar mal durante a noite. Sair dos limites do que é aprovado pelo outro - parente ou vizinho - faz com que os usuários deixem de realizar certas atividades, ainda que as desejem. As práticas tomadas como indevidas são evitadas, segundo Raia: “[dançar forró] a noite toda, Deus me livre?'.

Como entendem Miranda e Cabral (2016), a "condição de louco" funciona como um "filtro" na avaliação dos demais em relação à experiência da pessoa que é rotulada assim. Então, é construído um mundo repleto de limites para esses sujeitos, a quem não é permitido "querer ir à festa". Isso deságua na interdição das vontades desses sujeitos e da (im)possibilidade de circular em alguns lugares.

Outros locais de circulação dos usuários são igrejas, centros espíritas e demais espaços religiosos, como o Vale do Amanhecer, que Raia cita como um lugar onde se sente bem. Os usuários que frequentam o Vale também vão à igreja católica, como acontece com Raia e Márcia, onde se sentem bem. Henriques (2012) argumenta que as pessoas em sofrimento psí-

\footnotetext{
${ }^{5}$ Prostíbulo.

${ }^{6}$ O Vale do Amanhecer é, ao mesmo tempo, uma seita-religião, que apresenta elementos do espiritismo, da umbanda e do Santo Daime em suas celebrações. Foi fundada em 1959 pela clarividente Tia Neiva. A organização está presente em diversos pontos do Brasil e do mundo, embora o templo de Planaltina (DF) seja a sede (templo-mãe) (Galinkin, 2008).
} 
quico circulam por serviços religiosos, os utilizando como opção de cuidado, visando a saúde e a cura pela fé. Raia, Márcia e Branca vão a esses serviços para se sentirem bem, para cantar, dançar e aliviar seus sentimentos, emoções etc. Todas essas motivações também foram encontradas por Silveira (2008) em um trabalho sobre o atrativo dos serviços religiosos para os usuários dos serviços de saúde mental.

Bongiovanni e Silva (2019) atestam que a lógica manicomial presente na sociedade define o espaço de circulação dos sujeitos em sofrimento psíquico. Segundo Dunker (2004, citado por Bongiovanni \& Silva, 2019), o estímulo ao convívio dos iguais, "na lógica dos condomínios", ao invés de impedir a saída, impede a entrada dos considerados diferentes. Isso não acontece somente com pessoas em sofrimento psíquico, pois vivemos em um contexto em que imperam as privatizações e o individualismo; em que as trocas e os encontros se tornam cada vez mais frágeis. Nessa perspectiva, os autores ressaltam que é importante considerar outros marcadores de exclusão, como a pobreza. Evidentemente, em um contexto de enfraquecimento dos laços sociais, o desafio de superar o estigma social é bem maior para as pessoas em sofrimento psíquico, como também ressaltam os estudos de Salles e Miranda (2016).

Nesse sentido, destaca-se que, apesar de os participantes de nossa pesquisa afirmarem que circulam por vários lugares dentro da cidade, em outro momento, disseram carregar uma mancha que os marca, independentemente dos espaços que ocupem. Levar essa mancha invisível causa grande sofrimento para essas pessoas que são tomadas como diferentes das demais e classificadas pelo viés da loucura. Em uma das situações registradas nas rodas, Cesare diz: "apesar de trabalhar, de circular pela igreja, pela sorveteria, apesar de estudar, fica uma mancha que a gente leva pra vida toda".

É do estigma da "loucura" que Cesare fala. O estigma que carrega por onde for e que produz efeitos para a vida toda. Goffman (1988) adverte que o processo de formação do estigma se caracteriza justamente como uma marca, um símbolo atribuído às pessoas, que são incluídas em categorizações sociais e passam a ter atributos que indicam o que elas são ou podem ser. Essa mancha, que marca as pessoas em sofrimento psíquico, também foi descrita por um poeta japonês burakumin. Tal como relatado no estudo de Elias e Scotson (2000), o poeta burakumin questiona quem pôs essa marca que o acompanha por toda a vida:
Ouvi sussurrarem,

Como um sopro de vento de boca em boca,

Que abaixo de cada axila tenho uma marca do tamanho de uma mão espalmada ... Quem marcou meus flancos?

Por que causa ignorada? Por que esse estigma desconhecido em meu eu e minh'alma?

(Whitaker, Japan's Outcasts, p. 337 citado por Elias \& Scotson, 2000, p. 35).

Segundo os autores, os burakumin não carregam no corpo um sinal, todavia, são construídos historicamente como sujeitos que têm, abaixo das axilas, uma marca de suor proveniente dos trabalhos físicos realizados e que são considerados socialmente inferiores. Essa marca materializa sua exclusão, fazendo com que sejam tratados como anormais ou animais. É dessa exclusão que Cesare fala e da qual as pessoas em sofrimento psíquico tentam se desvincular diariamente, utilizando categorias como "deficiente", "doença psicológica”, "trauma”, dentre outras, como observado neste estudo.

\section{Considerações finais}

Ao se definir ou definir os que frequentam o CAPS como "deficientes" ou que apresentam uma "doença psicológica" ou um "trauma”, os usuários do serviço se posicionaram como quem sai da categoria de pessoas "loucas", que, em nossa sociedade, são a personificação da desrazão, tentando se aproximar de características das pessoas ditas normais. Mas as denominações "loucos" e "doidos" também foram mobilizadas pelos participantes da pesquisa para agredir outros usuários do CAPS, e, quando manejadas em um contexto de conflito, serviram para acusar ou até para amenizar o impacto de uma agressão verbal sofrida.

Outra expressão utilizada foi "pessoa fraca", o que torna essas pessoas emocionalmente vulneráveis quando são provocadas por outras que as cercam. Essa forma como a sociedade lida com as pessoas em sofrimento mental nos remete ao estigma da "loucura", com o qual os usuários lidam cotidianamente com intenso sofrimento, que cria barreiras para que eles construam projetos de vida. Todavia, a expressão "pessoa fraca" sugere um desarranjo emocional ameno, leve, e não representa algo exacerbado e fora de controle, mas uma instabilidade intensa vivenciada no cotidiano, que, frequentemente, é associada 
às pessoas que apresentam diagnóstico psiquiátrico. Afastando-se dessa possível instabilidade, os sujeitos se colocam no lugar dos que podem conviver em sociedade, logo, podem circular em vários espaços sociais, visto que não se colocariam como "perigo" para si e/ou para outras pessoas que estão em volta. Esse jogo retórico utilizado pelos participantes da pesquisa é importante, porque, ao recorrer a categorias como "pessoa fraca" ou "trauma", se diferenciam das pessoas “loucas”, "doidas”, “instáveis", passíveis de ser internadas em hospitais e clínicas psiquiátricas.

Os participantes da pesquisa também disseram que circulam por vários lugares de lazer e de entretenimento, como pizzarias, restaurantes, barezinhos, mas mencionaram dificuldades de sair dos limites do que é aprovado pelo outro, seja parente ou vizinho, como ir a festas de forró em outras cidades e passar a noite toda fora de casa, fazendo com que deixem de fazer determinadas atividades. As práticas consideradas indevidas são evitadas, possivelmente porque eles têm medo de entrar em outro processo de adoecimento ou de praticar ações consideradas erradas e de voltar para o hospital psiquiátrico. Outros locais de circulação dos usuários são igrejas, centros espíritas e o Vale do Amanhecer (templo espírita), também utilizados como espaços de cuidado em saúde.

Ressalte-se que os participantes da pesquisa também definiram a si mesmos como pessoas que levam para a vida toda uma "mancha", embora procurem se apresentar como pessoas comuns, iguais a todas as outras, que adoecem, sofrem, vivem e podem circular por vários lugares, não apenas nos hospitais, nos CAPS ou em outros serviços de saúde. Pode-se concluir que esses usuários, com evidente habilidade retórica, utilizaram categorias discursivas para compreender sua situação e, ao mesmo tempo, combaterem o processo de estigmatização a que estão submetidos.

As instituições, os ativistas e os pesquisadores que participam da luta antimanicomial e querem construir práticas emancipatórias de fato devem investigar profundamente a mobilização dessas categorias discursivas nos relatos dos usuários de serviços substitutivos. Esses sujeitos precisam ser escutados, reconhecidos, legitimados para que possamos retomar os princípios da Reforma Psiquiátrica, pautados na liberdade, no respeito e na autonomia das pessoas em sofrimento psíquico e fortalecer o combate a práticas manicomiais e excludentes, propostas pela nova Política Nacional de Saúde Mental (PNSM).

\section{Referências}

Amarante, P. (2007). Saúde mental e atenção psicossocial. Editora Fiocruz.

Amarante, P., \& Nunes, M. O. (2018). A reforma psiquiátrica no SUS e a luta por uma sociedade sem manicômios. Ciência \& Saúde Coletiva, 23(6), 20672074. https:// doi.org/10.1590/1413-81232018236.07082018

Amarante, P., \& Torre, E. H. G. (2017). Loucura e diversidade cultural: Inovação e ruptura nas experiências de arte e cultura da Reforma Psiquiátrica e do campo da Saúde Mental no Brasil. Interface: Comunicação, Saúde, Educação, 21(63), 76374. https://doi.org/10.1590/1413-81232018236.07082018

Associação Brasileira de Saúde Coletiva. (2017, 11 de dezembro). Nota contra os retrocessos da CGMAD/MS frente à política brasileira de Saúde Mental. https://www.abrasco.org.br/site/noticias/posicionamentos-oficiais/ retrocessos-saude-mental-governo-temer/32436/

Associação Brasileira de Saúde Mental. (2019). Abrasco e Abrasme marcam presença no debate sobre Saúde Mental. https://www.abrasco.org.br/site/noticias/sistemas-de-saude/abrasco-e-abrasme-marcam-presenca-no-debate-sobre-mudancas-na-politica-de-saude-mental/39484/

Aurélio, B. H. (2010). Dicionário da língua portuguesa (5a ed.). Positivo.

Barbosa, V. F. B., Caponi, S. N., \& Verdi M. I. M. (2018). Risco como perigo persistente e cuidado em saúde mental: Sanções normalizadoras à circulação no território. Saúde e Sociedade, 27(1), 175184. https://doi.org/10.1590/ S0104-12902018170233

Barros-Brisset, F. O. (2011). Genealogia do conceito de periculosidade. Responsabilidades, 1(1), 3752. https://bd.tjmg.jus.br/jspui/bitstream/tjmg/582/7/Responsabilidades-v1-n1.pdf

Barroso, A. G. C., Abreu, L. M., Bezerra, M. A. A., Ibiapina, S. L. D., \& Brito, H. B. (2004). Transtornos mentais: O significado para os familiares. Revista Brasileira em Promoção da Saúde, 17(3), 99108. https://periodicos.unifor.br/ RBPS/article/view/686 
Figueirêdo, A. A. F., Cordeiro, R. L. M., Oliveira Filho, P., \&Velôso, T. M. G. (2021). Construção de Categorias/Lugares para a Loucura.

Basaglia, F. (2005). Escritos selecionados: Em saúde mental e Reforma Psiquiátrica. Editora Garamond.

Billig, M. (1987). Arguing and thinking: A rhetorical approach to social psychology. Cambridge University Press.

Bongiovanni, J., \& Silva, R. A. N. (2019). Desafios da desinstitucionalização no contexto dos serviços substitutivos de saúde mental. Psicologia \& Sociedade, 31, 114. https://doi.org/10.1590/1807-0310/2019v31190259

Brasil. (2001, 9 de abril). Lei no 10.216 de 06 de abril de 2001. Diário Oficial da União. https:/ /www.planalto.gov.br/ ccivil_03/leis/leis_2001/110216.htm

Brasil. Ministério da Saúde. (2019, 4 de fevereiro). Secretaria de Atenção à Saúde. Departamento de Ações Programáticas Estratégicas. Coordenação-Geral de Saúde Mental, Álcool e Outras Drogas. Nota Técnica no 11/2019. http://cetadobserva.ufba.br/sites/cetadobserva.ufba.br/files/nota_tecnica_-_esclarecimentos_sobre_as_ mudancas_da_politica_de_saude_mental.pdf

Brasil. (2004). Saúde mental no SUS: Os centros de atenção psicossocial. Ministério da Saúde. https://www.nescon. medicina.ufmg.br/biblioteca/imagem/1212.pdf

Chaves, L. L. (2009). "Esse negócio de loucura, cê sabe né, fia": Integração e diferenciação pelas ruas de Ouro Preto [Dissertação de Mestrado, Universidade de Brasília]. Repositório Institucional da UnB. https://repositorio.unb.br/ handle/10482/4459

Conselho Federal de Enfermagem. (2017, 30 de dezembro). Cofen não aceita o retrocesso na saúde mental. http:// www.cofen.gov.br/cofen-nao-aceita-o-retrocesso-na-saude-mental_59609.html

Conselho Federal de Psicologia. (2017). Posicionamento do Sistema Conselhos contrário ao Plano Nacional de Saúde Mental. http://site.cfp.org.br/wp-content/uploads/2017/12/Posicionamento-do-Sistema-Conselhos-contrário-ao-Plano-Nacional-de-Saúde-Mental.pdf

Conselho Nacional de Saúde. (2018). Recomendação n. 001, 31 de janeiro de 2018. http://conselho.saude.gov.br/ recomendacoes/2018/Reco001.pdf

Conselho Nacional dos Direitos Humanos. (2019). Recomendação no 03, de 14 de março de 2019. https://www. conass.org.br/conass-informa-n-83-publicada-a-recomendacao-n-3-do-cndh-que-recomenda-que-todas-as-normativas-incompativeis-com-a-estabelecida-politica-nacional-de-saude-mental-que-subsidiam-a-nova/

Comerford, J. C. (2003). Como uma família: Sociabilidade, territórios de parentesco e sindicalismo rural. Relume Dumará.

Cruz, N. F. O., Gonçalves, R. W., \& Delgado, P. G. G. (2021). Retrocesso da Reforma Psiquiátrica: o desmonte da política nacional de saúde mental brasileira de 2016 a 2019. Trabalho, Educação e Saúde, 18(3). 10.1590/1981-7746-sol00285

Delgado, P. G. (2019). Reforma psiquiátrica: Estratégias para resistir ao desmonte. Trabalho, Educação e Saúde, 17(2), 1-4. https://doi.org/10.1590/1981-7746-sol00212

Desviat, M. (2008). A reforma psiquiátrica (10a ed.). Editora Fiocruz.

Duarte, L. F. D. (1986). Da vida nervosa nas classes trabalhadoras urbanas. Jorge Zahar.

Elias, N., \& Scotson, J. L. (2000). Os estabelecidos e os outsiders: Sociologia das relações de poder a partir de uma pequena comunidade. Jorge Zahar.

Foucault, M. (1975). Doença mental e psicologia. Tempo Brasileiro.

Foucault, M. (1992). Microfísica do poder (10a ed.). Graal.

Foucault, M. (2010). História da loucura na Idade Clássica (9a ed.). Perspectiva.

Galinkin, A. L. (2008). A cura no Vale do Amanhecer. TechnoPolitic.

Gill, R. (2008). Análise de discurso. In M. W. Bauer, \& G. Gaskell (Orgs.), Pesquisa qualitativa com texto, imagem e som um manual prático (pp. 244270). Vozes.

Goffman, E. (1988). Estigma: Notas sobre a manipulação da identidade deteriorada. Guanabara.

Grigolo, T. M. (2000). "Dizem que sou louco": Um estudo sobre identidade e instituição psiquiátrica. Revista de Ciências Humanas, (4), 95119. https://periodicos.ufsc.br/index.php/revistacfh/article/view/25765/22562

Grigolo, T. M. (2010). "O Caps me deu voz, me deu escuta": Um estudo das dimensões da clínica nos Centros de Atenção Psicossocial na perspectiva de trabalhadores e usuários [Tese de Doutorado, Universidade de Brasília]. Repositório Institucional da UnB. https://repositorio.unb.br/handle/10482/7193 
Henriques, H. I. B. (2012). Igreja e serviço de saúde mental: Um estudo das narrativas de evangélicos, usuários de Caps [Dissertação de Mestrado, Universidade Federal de Pernambuco]. Attena Repositório Digital da UFPE. https://repositorio.ufpe.br/handle/123456789/11118

Instituto Brasileiro de Geografia e Estatística. (2010). IBGE Cidades: Itaporanga. http://www.ibge.gov.br/cidadesat/ painel/painel.php?codmun=250700

Peres, G. M., Moser, K. L., Oltramari, L. C, \& Rodriguez, J. (2012). Representações sociais do louco/loucura para estudantes de nível fundamental. Saúde \& Transformação Social, 3(2), 96-103. http://incubadora.periodicos.ufsc.br/ index.php/saudeetransformacao/article/view/1487/1776

Martins, R. C. A. (2019). Reformas psiquiátricas e o processo de ressignificação do trabalho de saúde mental. Revista do NUFEN, 11(2), 96116. https://dx.doi.org/10.26823/RevistadoNUFEN.voll1.n02ensaio50

Ministério da Saúde. (2002). Portaria n. ${ }^{\circ}$ 336, de 19 de fevereiro de 2002. https:/ /bvsms.saude.gov.br/bvs/saudelegis/ gm/2002/prt0336_19_02_2002.html

Ministério da Saúde. (2005, 7-10 de novembro). Reforma psiquiátrica e política de saúde mental no Brasil. Conferência Regional de Reforma dos Serviços de Saúde Mental: 15 anos depois de Caracas, Brasília, DF. https:/ /bvsms. saude.gov.br/bvs/publicacoes/Relatorio15_anos_Caracas.pdf

Miranda, A. C. S., \& Cabral, B. E. B. (2016). Vozes da loucura: Reflexões críticas a partir de narrativas de pessoas que viveram uma internação psiquiátrica. Cadernos Brasileiros de Saúde Mental, 8(19), 42-66.

Moraes, L. N., Dos-Santos, E., Reis, H. F. T., Silva, M. R. A., Vianna, P. C. M., \& Kurimoto, T. C. S. (2018). A loucura e a sua verdade em questão: Discursos de profissionais de enfermagem da atenção hospitalar. Revista Portuguesa de Enfermagem de Saúde Mental, (19), 2736. https://dx.doi.org/10.19131/rpesm.0199

Oliveira, R. T., \& Rodrigues, W. (2016). A política, o social e a clínica enquanto saídas para a desconstrução dos manicômios e do mito da periculosidade. In E. Venturini, R. T. Oliveira, \& V. Mattos (Orgs.), O louco infrator e o estigma da periculosidade (pp. 314352). CFP. https://site.cfp.org.br/wp-content/uploads/2016/11/ CFP_Livro_LoucoInfrator_web-2.pdf

Pacheco, J. G. (2011). Representações sociais da loucura e práticas sociais: O desafio cotidiano da desinstitucionalização [Tese de Doutorado, Universidade de Brasília]. Repositório Institucional da UnB. https://repositorio.unb.br/ handle/10482/10194

Pessotti, I. (1999). Os nomes da loucura. Editora 34.

Potter, J. (1998). La representación de la realidad: Discurso, retórica y construcción social. Paidós.

Potter, J., \& Hepburn, A. (2007). Discursive psychology: Mind and reality in practice. In A. Weatherall, B. Watson, \& C. Gallois (Eds), Language, discourse and social psychology (pp. 160181). Palgrave Macmillan.

Potter, J., \&Wetherell, M. (1987). Discourse and social psychology. Sage.

Prado, G. A. S. (2016). Revisitando a história da loucura: Experiência trágica, exclusão, captura e tutela. Estudos Contemporâneos da Subjetividade, 6(2), 223238. http://www.periodicoshumanas.uff.br/ecos/article/viewFile/1855/1326

Salles, A. C. R. R., \& Miranda, L. (2016). Desvincular-se do manicômio, apropriar-se da vida: Persistentes desafios da desinstitucionalização. Psicologia \& Sociedade, 28(2), 369379. https:// doi.org/10.1590/ 1807-03102016v28n2p369

Sander, J. (2010). A caixa de ferramentas de Michel Foucault, a reforma psiquiátrica e os desafios contemporâneos. Psicologia \& Sociedade, 22(2), 382387. https://doi.org/10.1590/S0102-71822010000200019

Silva, J. S. (2012). Família e transtorno mental: Um estudo com familiares de usuários de um Caps [Dissertação de Mestrado, Universidade Federal de Pernambuco].

Silveira, L. (2008). Para além de anjos, loucos ou demônios: Um estudo sobre modos de subjetivação da loucura, a partir das experiências religiosas de usuários de um Caps, nas Igrejas pentecostais, em um município do interior da Bahia [Dissertação de Mestrado, Universidade Federal da Bahia]. Repositório Institucional UFBA. https://repositorio.ufba.br/ri/handle/ri/10402

Vechi, L. G. (2004). Iatrogenia e exclusão social: A loucura como objeto do discurso científico no Brasil. Estudos de Psicologia, 9(3), 489-495. https://doi.org/10.1590/S1413-294X2004000300011

Vieceli, A. P. (2014). Lugares da loucura: O reencontro da cidade com a diferença [Texto Completo]. III Encontro da Associação Nacional de Pesquisa e Pós-graduação em Arquitetura e Urbanismo: arquitetura, cidade e pro- 
Figueirêdo, A. A. F., Cordeiro, R. L. M., Oliveira Filho, P., \& Velôso, T. M. G. (2021). Construção de Categorias/Lugares para a Loucura.

jeto: uma construção coletiva, São Paulo. http://www.anparq.org.br/dvd-enanparq-3/htm/Artigos/SC/ORAL/ SC-EPC-015_VIECELI.pdf

Wetherell, M., \& Potter, J. (1992). Mapping the language of racism: Discourse and the legitimation of exploitation. Harvester Wheatsheaf.

Alessandra Aniceto Ferreira de Figueirêdo

Doutora em Saúde Coletiva pelo Instituto de Medicina Social Hésio Cordeiro da Universidade do Estado do Rio de Janeiro (UERJ), Rio de Janeiro - RJ. Brasil.

E-mail: alessandra_aniceto@yahoo.com.br

(1) https://orcid.org/0000-0003-2156-9055

Rosineide de Lourdes Meira Cordeiro

Doutora em Psicologia Social pela Pontifícia Universidade Católica de São Paulo (PUC-SP), São Paulo - SP. Brasil.

E-mail: rosineidecordeiro2017@gmail.com

(1) https:// orcid.org/0000-0001-6487-4012

Pedro de Oliveira Filho

Doutor em Psicologia Social pela Pontifícia Universidade Católica de São Paulo (PUC-SP), São Paulo -SP. Brasil.

E-mail: deoliveirafilhopedro@gmail.com

(1) https://orcid.org/0000-0003-2401-8953

Thelma Maria Grisi Velôso

Doutora em Sociologia pela Universidade Estadual Paulista Júlio de Mesquita Filho (Unesp), Araraquara -SP. Brasil.

E-mail: tgrisiveloso@gmail.com

(1) https://orcid.org/0000-0003-0447-7490

Agradecimentos e fonte de financiamento (se houver).

Agradecimento à Coordenação de Aperfeiçoamento de Pessoal de Nível Superior (CAPES), que financiou esta pesquisa.

Endereço para envio de correspondência:

Universidade Federal do Rio de Janeiro, Campus Macaé, Polo Universitário. Rua Aloísio da Silva Gomes, 50, Granja dos Cavaleiros. CEP: 27930-560. Macaé - RJ. Brasil.

Recebido $13 / 10 / 2018$

Aceito 17/03/2020

Received 10/13/2018

Approved 03/17/2020

Recibido 13/10/2018

Aceptado 17/03/2020 
Como citar: Figueirêdo, A. A. F., Cordeiro, R. L. M., Oliveira Filho, P., \&Velôso, T. M. G. (2021). Construção de categorias/lugares para a loucura em relatos de usuários de CAPS. Psicologia: Ciência e Profissão, 41 (n.spe 4), 1-16. https://doi.org/10.1590/1982-3703003215322

How to cite: Figueirêdo, A. A. F., Cordeiro, R. L. M., Oliveira Filho, P., \& Velôso, T. M. G. (2021). Construction of categories/places for madness in the reports of users of psychosocial care centers. Psicologia: Ciência e Profissão, 41 (n.spe 4), 1-16. https:// doi.org/10.1590/1982-3703003215322

Cómo citar: Figueirêdo, A. A. F., Cordeiro, R. L. M., Oliveira Filho, P., \& Velôso, T. M. G. (2021). Construcción de categorías/lugares para la locura en relatos de usuarios del CAPS. Psicologia: Ciência e Profissão, 41 (n.spe 4), 1-16. https://doi.org/10.1590/1982-3703003215322 